\title{
Measured Versus Predicted Resting Metabolic Rate in Obese Diabetic and Obese Non-Diabetic Subjects
}

\author{
Tarig H Merghani ${ }^{1}$, Azza O Alawad ${ }^{2}$, Ballal MA ${ }^{3}$ \\ ${ }^{1,2}$ (Department of Physiology, Faculty of Medicine, University of Tabuk, Saudi Arabia) \\ ${ }^{3}$ (Department of Physiology, Faculty of Medicine, University of Science and Technology, Sudan)
}

\begin{abstract}
Predictive equations provide the basis for estimating energy needs for different individuals; however, accuracy of these equations has been questioned in tropical countries. The current study determined which of the commonly used predictive equations is most suitable for estimating resting metabolic rate (RMR) in a random sample of obese diabetic and obese non-diabetic subjects in Sudan. Two matched samples of 40 obese diabetic and 40 obese non-diabetic subjects, aged 35 to 50 years old, were randomly selected. The PowerLab $8 / 35$ with a gas analyzer (ADInstruments, Castle Hill Australia) was used for measurement of $\mathrm{O}_{2}$ consumption and $\mathrm{CO}_{2}$ production for each participant. RMR was derived from these parameters using Weir's formula. Three predictive equations (Harris-Benedict, Mifflin and Food and Agriculture Organization/World Health Organization/ United Nations University (FAO/WHO/UNU) were compared with the measured RMR to determine their accuracy in predicting RMR for the two groups. Unlike the other two equations, Mifflin's equation showed insignificant statistical difference between measured and predicted RMR in obese diabetic patients; however, none of the three equations gave accurate results for the obese non-diabetic individuals. It is recommended that a new predictive equation should be developed for estimating RMR in the obese non-diabetic individuals.
\end{abstract}

Keywords: Obesity, Diabetes mellitus, Resting metabolic rate, Indirect calorimetry, Weir's formula, Predictive equations

\section{INTRODUCTION}

Resting metabolic rate (RMR) is the amount of energy released from a resting subject per unit time. The release and utilization of energy in this state is sufficient primarily for functioning of the vital organs. Measurement of RMR is essential for nutritional assessment, weight loss planning and management of various medical conditions. Because of the increasing worldwide awareness about its importance, a free metabolic rate calculator, based on one of the predictive equations, was recently released as a new application for advanced mobile phones [1]. In addition to providing an easy and rapid calculation of basal metabolic rate, this software program application serves to spread knowledge about energy expenditure to a large number of people, especially those who use this sort of modern technology.

The primary method for metabolic rate measurement is indirect calorimetry whereby oxygen consumption and carbon dioxide production in expired air are directly measured for calculation of energy expenditure. RMR is derived from these parameters with the Weir formula which is widely used for metabolic rate calculations [2,3]. Predictive equations like Harris-Benedict [4,5], Food and Agriculture Organization/World Health Organization/United Nations University( FAO/ WHO/UNU)[6], and Mifflin [7] equations, which were introduced in 1918, 1985 and 1990 respectively, are still widely used for calculation of resting energy expenditure. These equations are simple, easy to use, and universally available. However, in spite of their extensive use, they have been found to be inaccurate in a variety of clinical settings [8,9]. While the Harris-Benedict equation had been used for estimating the basal metabolic rate, previous studies have found that it estimates RMR rather than basal metabolic rate, due to the test subjects not spending the night at the test facility [10]. The Mifflin equation, tested in different settings worldwide, has been shown to produce more accurate estimations for RMR than other predictive equations [8-11]. It has been recommended as the standard equation for calculating RMR in healthy obese and non-obese adults [10]. However, contradictory results have been recently reported from data obtained in tropical countries [12]. FAO/WHO/UNU equations, which are based on the work of Schofield et al, were developed from older research conducted in western communities [13]. Their validity in the estimation of resting energy expenditure worldwide needs to be re-evaluated.

In clinical practice, predictive equations provide the basis for estimating energy needs for different individuals. However, a number of predictive equations were found to be inaccurate in obese subjects especially those with diabetes $[5,14,15]$. In Sudan, there is paucity of data regarding which equation should be used. On the other hand, the finding that basal metabolic rate values in African Americans were lower than values in Caucasians [16], has indicated a genetic variation in energy expenditure between individuals. Consistence with this, a previous survey showed lower basal metabolic rate values of people in the tropics as compared to values 
estimated with WHO predictive equations [17]. The researchers recommended further evaluation of energy requirements in people living in tropical climates. Thus, the aim of the current study was to determine which predictive equation does not differ from indirect calorimetry in estimating RMR in both obese diabetic and obese non-diabetic subjects.

\section{METHODS}

This study was conducted in Jabir Abu-Eliz centre in Khartoum- Sudan, in the period between January to August 2012. A random sample of 40 obese diabetic patients and 40 obese non-diabetic subjects were selected from patients attending for follow up of their diabetes and from their healthy relatives respectively. Inclusion criteria for both groups were adult, 35 to 50 years old, body mass index $\geq 30$, non-smoker, normotensive, afebrile and with no symptoms or signs of acute or chronic infection. Cases were known to be diabetic for at least one year, whereas controls were non-diabetic. Both groups were matched according to age, sex, height, weight, surface area and area of residence. Each participant completed an anonymous interviewerbased questionnaire; to obtain information about present health status. Clinical examination excluded presence of abnormal clinical signs. Height and weight of each participant was measured using standardized height and weight scales. The PowerLab 8/35 (ADInstruments, Castle Hill Australia) data acquisition system, comprising hardware and software, was used with bio amplifier, thermistor, spirometer, gas analyzer, gas mains chamber and a computer windows 7 program to record and analyze physiological signals from participants. The system allowed measurement of oxygen consumption (VO2), carbon dioxide production (VCO2), respiratory ventilation (VE) and respiratory exchange ratio (RER). All participants fasted overnight and were allowed to rest in a thermally neutral room for $30 \mathrm{~min}$ before measurements. Each test took about $20 \mathrm{~min}$, with at least 5 min steady state. The steady state was defined as minimal variation $(<10 \%)$ in VO2, VCO2, VE and RER. RMR was calculated using Weir's formula-[2,3] as follows: RMR (kcal/day) $=5.46 \mathrm{VO} 2+1.75 \mathrm{VCO}$. Three predictive equations ("Harris-Benedict", "FAO/WHO/UNU" and "Mifflin" were assessed for their accuracy in predicting RMR among all participants in the study. RMR (kcal/day) using:

The Harris-Benedict equation [4,5]:

$(13.7516 \mathrm{wt} / 1 \mathrm{~kg}+5.0033 \mathrm{ht} / 1 \mathrm{~cm}-6.7550 \mathrm{age} / 1$ year +66.4730$)$ for men

$(9.5634 \mathrm{wt} / 1 \mathrm{~kg}+1.8496 \mathrm{ht} / 1 \mathrm{~cm}-4.6756 \mathrm{age} / 1$ year +655.0955$)$ for women

The FAO/WHO/UNU equation [6]:

$(11.6 \mathrm{X}$ weight +879$)$ for males in the age group from 31 to 60 years old

$(8.7 \mathrm{X}$ weight +829$)$ for females in the age group from 31 to 60 years old

The Mifflin equation [7]:

$(10.0 \mathrm{wt} / 1 \mathrm{~kg}+6.25 \mathrm{ht} / 1 \mathrm{~cm}-5.0 \mathrm{age} / 1$ year $+\mathrm{s})$; where $\mathrm{s}$ is +5 for males and -161 for females

All procedures conformed to the ethical principles of medical research as developed by the World Medical Association Declaration of Helsinki [18]. Ethical clearance was given by the institutional Research Committee (Faculty of Medicine/ University of Al-Neelain- Sudan) and approval was obtained from the Ministry of Health. Written consents were obtained from each participant before entry into the study. All data obtained were analysed using the Statistical Package for the Social Sciences V.16 (SPSS Inc.). Differences in mean RMR between diabetic and non-diabetic individuals were analysed with the independent student's $t$ tests. Comparisons between measured and predicted RMR were determined with paired student's $t$ tests. Statistical significance was accepted for $\mathrm{p} \leq 0.05$.

\section{RESULTS}

Table 1 describes characteristics of participants in the study group. The two groups did not differ in age, gender, height, weight, body mass index and surface area. Table 2 shows measured and predicted RMR in diabetic and non-diabetic participants. Measured RMR (mean \pm SD in kcal/day) was significantly higher ( $\mathrm{p}=$ $0.027)$ among diabetic $(1480.7 \pm 274.2)$ as compared to the non-diabetic (1362.4 \pm 184.8$)$ patients. No differences were found between the two groups in predicted RMR with the three equations. Among the diabetic patients, the difference in means between predicted and measured RMR was $11 \%$ for Harris-Benedict equation (table 3), 4.5\% for Mifflin equation (table 4), and 14\% for FAO/WHO/UNU equation (table 5). Among the nondiabetic participants, the mean differences were $24 \%, 17 \%$, and $26 \%$ for Harris-Benedict, Mifflin and $\mathrm{FAO} / \mathrm{WHO} / \mathrm{UNU}$ equations respectively. In obese diabetic patients, no difference was seen between measured RMR and that predicted with Mifflin equation (table 4). 
Table 1: Characteristics of participants in the study group

\begin{tabular}{|c|c|c|c|}
\hline Parameter & Study group & & $P$ value \\
\hline Age & Diabetics & $45.03 \pm 5.09$ & \multirow{2}{*}{0.564} \\
\hline$($ mean $\pm \mathrm{SD}) \mathrm{y}$ & Non-diabetics & $44.33 \pm 5.69$ & \\
\hline Gender & Diabetics & $2: 3$ & \multirow{2}{*}{1.000} \\
\hline (Male: Female) ratio & Non-diabetics & $2: 3$ & \\
\hline Height & Diabetics & $1.63 \pm 0.08$ & \multirow{2}{*}{0.094} \\
\hline$($ mean $\pm \mathrm{SD}) \mathrm{cm}$ & Non-diabetics & $1.66 \pm 0.08$ & \\
\hline Weight & Diabetics & $85.00 \pm 7.70$ & \multirow{2}{*}{0.486} \\
\hline$($ mean $\pm \mathrm{SD}) \mathrm{kg}$ & Non-diabetics & $86.52 \pm 11.35$ & \\
\hline BMI & Diabetics & $32.04 \pm 2.08$ & \multirow{2}{*}{0.328} \\
\hline $\mathrm{kg} / \mathrm{m}^{2}$ & Non-diabetics & $32.29 \pm 2.06$ & \\
\hline Surface area & Diabetics & $1.96 \pm 0.128$ & \multirow{2}{*}{0.078} \\
\hline$($ mean $\pm S D) m^{2}$ & Non-diabetics & $2.01 \pm 0.126$ & \\
\hline
\end{tabular}

The two groups did not differ in age, gender, height, weight, body mass index and surface area.

Table 2: Comparison in resting energy expenditure between obese diabetic and obese non-diabetic participants

\begin{tabular}{lllc}
\hline $\begin{array}{l}\text { Measurement } \\
\text { method/equation }\end{array}$ & Study group & $\begin{array}{l}\text { Resting metabolic rate } \\
(\text { mean } \pm \text { SD) kcal/day }\end{array}$ & \multicolumn{1}{c}{$\begin{array}{l}\text { Confidence intervals } \\
\text { kcal/day }\end{array}$} \\
\hline Indirect calorimetry & Diabetics $(\mathrm{n}=40)$ & $1480.7 \pm 274.2$ & $1393.0-1568.4$ \\
& Non-diabetics $(\mathrm{n}=40)$ & $1362.4 \pm 184.8$ & $1303.3-1421.5$ \\
Harris-Benedict & Diabetics $(\mathrm{n}=40)$ & $1646.6 \pm 176.4$ & $1590.1-1703.0$ \\
& Non-diabetics $(\mathrm{n}=40)$ & $1689.3 \pm 195.7$ & $1627.0-1751.9$ \\
Mifflin & Diabetics $(\mathrm{n}=40)$ & $1547.6 \pm 170.3$ & $1493.2-1602.1$ \\
& Non-diabetics $(\mathrm{n}=40)$ & $1598.1 \pm 177.0$ & $1541.5-1654.6$ \\
FAO/WHO/UNU & Diabetics $(\mathrm{n}=40)$ & $1691.6 \pm 194.6$ & $1629.3-1753.8$ \\
& Non-diabetics $(\mathrm{n}=40)$ & $1719.2 \pm 195.1$ & 0.308 \\
\hline
\end{tabular}

Indirect calorimetry showed significantly higher $(p=0.027)$ resting metabolic rate in obese diabetic patients as compared to the non-diabetic, while no differences were found between the two groups with the three predictive equations.

Table 3: Indirect calorimetry versus Harris-Benedict's equation in calculation of resting metabolic rate

\begin{tabular}{lllll}
\hline & & \multicolumn{3}{c}{ Resting metabolic rate $(\mathrm{kcal} /$ day $)$} \\
Obese non-diabetic $(\mathrm{n}=40)$ \\
\hline Parameter & Indirect Calorimetry & Harris-Benedict's equation & Indirect Calorimetry & Harris-Benedict's equation \\
\hline Minimum & 1155.6 & 1403.5 & 1057.3 & 1465.4 \\
Maximum & 2238.8 & 2085.0 & 1787.3 & 2189.6 \\
Mean $\pm \mathrm{SD}$ & $1480.7 \pm 274.2$ & $1646.6 \pm 176.4$ & $1362.4 \pm 184.8$ & $1689.3 \pm 195.7$ \\
Difference & $11 \%$ & & $24 \%$ & \\
P value & 0.001 & & 0.000 &
\end{tabular}

The Harris-Benedict equation significantly overestimates $(p<0.05)$ resting metabolic rate in the two groups.

Table 4: Indirect calorimetry versus Mifflin's equation in calculation of resting metabolic rate

\begin{tabular}{|c|c|c|c|c|}
\hline \multicolumn{5}{|c|}{ Resting metabolic rate (kcal/day) } \\
\hline \multicolumn{2}{|c|}{ Obese diabetic $(n=40)$} & \multicolumn{3}{|c|}{ Obese non-diabetic $(n=40)$} \\
\hline Parameter & Indirect Calorimetry & Mifflin's equation & Indirect Calorimetry & Mifflin's equation \\
\hline Minimum & 1155.6 & 1260.3 & 1057.3 & 1354.0 \\
\hline Maximum & 2238.8 & 1941.3 & 1787.3 & 2023.8 \\
\hline Mean $\pm \mathrm{SD}$ & $1480.7 \pm 274.2$ & $1547.6 \pm 170.3$ & $1362.4 \pm 184.8$ & $1598.1 \pm 177.0$ \\
\hline Difference $(\%)$ & $4.5 \%$ & & $17 \%$ & \\
\hline $\mathrm{P}$ value & 0.164 & & 0.000 & \\
\hline
\end{tabular}

In obese diabetic participants, but not the obese non-diabetic, no difference was seen between measured RMR and that predicted with the Mifflin equation.

Table 5: Indirect calorimetry versus FAO/WHO/UNU equation in calculation of resting metabolic rate

\begin{tabular}{llll}
\hline & Obese diabetic $(\mathrm{n}=40)$ & \multicolumn{2}{c}{ Resting metabolic rate $(\mathrm{kcal} /$ day) } \\
Obese non-diabetic $(\mathrm{n}=40)$
\end{tabular}

The FAO/WHO/UNU equation significantly overestimates $(p<0.05)$ resting metabolic rate in the two groups. 
IV

\section{DISCUSSION}

The measurement of energy expenditure is an important element in estimation of energy requirements. In addition to its importance in scientific research, it has become an essential tool in maintenance of a healthy body weight. Obese subjects, especially those with type II diabetes mellitus, may need special consideration because insulin resistance in these individuals is associated with abnormal metabolic reactions in skeletal muscle, liver, and adipose tissue that alters their metabolic rate. In the present study, we found that RMR was significantly higher among obese diabetic patients as compared to the non-diabetic controls. A similar finding was reported by Weyer and colleagues, who described a progressive increase in RMR with progressive deterioration of glucose tolerance [19]. Other researchers have attributed weight loss that is often observed in Type 2 diabetic subjects to higher energy expenditure in addition to the energy loss from glycosuria [20]. Additional similar results have been recently reported in severely obese diabetic patients [21]. These researchers suggested a new predictive equation for calculation of RMR in diabetic patients using gender, age, height, weight and diabetes mellitus as variables [21]. In an earlier study, race had been suggested as a key variable [22] while fasting blood sugar has also been suggested [23]. The inconsistent results and the different variables suggested in these studies indicate that estimation of RMR in obese diabetic patients using predictive equations may be misleading and requires further investigations.

Several mechanisms have been proposed to explain the rise in resting energy expenditure among diabetic patients. One of these mechanisms is an increase in gluconeogenesis [24]. A positive correlation has been reported between free fatty acid concentration in the plasma and release of glucose from the liver in diabetic patients $[19,25]$. Furthermore, previous studies reported a reduction in resting energy expenditure following improvement in glycemic control [26]. Other proposed mechanisms for the higher RMR in diabetic patients include abnormal protein metabolism [27], increased sympathetic activity [28] and hyperglucagonaemia [29].

Calculation of RMR using Weir's derivation showed a difference between diabetic and non-diabetic subjects, whereas no difference emerged when the three predictive equations were used. These equations are not expected to detect difference in energy expenditure between two matched groups because of similar variables. For this reason, development of new predictive equations that include diabetes mellitus or fasting blood sugar as additional variables is justified [21,23].

The mean RMR values estimated with these predictive equations were higher in both diabetic and nondiabetic subjects as compared to the mean values measured with indirect calorimetry. This finding confirms results of previous studies that described overestimation of RMR when calculated with predictive equations $[30,31]$. According to our results, the Harris-Benedict equation overestimated the RMR among diabetic patients by about $11 \%, \mathrm{FAO} / \mathrm{WHO} / \mathrm{UNU}$ equations by $14 \%$, and the Mifflin equation overestimated it by only $4.5 \%$. Statistical analysis confirmed that the Mifflin equation is more suitable than the other equations for estimating RMR among obese diabetic patients. Similar findings were reported in many previous studies [8-11,30,31]. On the other hand, although differences between measured and predicted RMR in obese non-diabetic individuals is lowest for Mifflin equation, statistical analysis showed significant difference between the two methods. This indicates the need for developing new predictive equation for RMR estimation in obese people living in the tropics.

\section{CONCLUSION}

This study showed that the RMR rate is higher in obese diabetic patients compared to obese nondiabetic individuals. Predictive equations were unlikely to detect difference in RMR between diabetic and nondiabetic subjects. The Mifflin equation is more reliable than Harris-Benedict and FAO/WHO/UNU equations in estimating RMR in obese diabetic patients. A new predictive equation is needed for obese non-diabetic individuals.

\section{Acknowledgements}

We would like to thank the Department of Physiology/ Al-Neelain University- Sudan for allowing us to use departmental equipment. We would like to extend our thanks to the Ministry of Health and to the administration staff of Gabir Abu-Eliz centre in Khartoum for their kind permission and close supervision during the process of data collection. We would like to express our gratitude and special thanks to Professor Ronald See for revising the language of the manuscript. We would also like to extend our appreciation and thanks to the participants for their understanding and cooperation. 


\section{REFERENCES}

[1] MMISoftware Blog. Three basal metabolic rate calculator for the iphone. Internet: http://www.mmisoftware.co.uk/weblog/2009/08/30/three free basal metabolic rate calculator for the iphone/ accessed 12 December 2012 .

[2] deWeir JB. New Methods for Calculating Metabolic Rate with Special Reference to Protein Metabolism. J Physiol, 1949; 109:1 -9.

[3] Mansell PI, Macdonald IA. Reappraisal of the Weir's equation for calculation of metabolic rate. AJP - Regu Physiol, 1990; 258:R1347-R1354.

[4] Harris J, Benedict F. a biometric study of human basal metabolism. Proc Natl Acad Sci, 1918; 4:370-3.

[5] Frankenfield DC, Muth ER, Rowe WA. The Harris-Benedict studies of human basal metabolism: history and limitations. J Am Diet Assoc, 1998; 98:439-445.

[6] FAO/WHO/UNU. Energy and Protein Requirements. Report of a Joint FAO/WHO/UNU Expert Consultation. Technical Report Series No. 724. Geneva: World Health Organization, 1985.

[7] Mifflin MD, St Jeor ST, Hill LA, Scott BJ, Daugherty SA, Koh YO. A new predictive equation for resting energy expenditure in healthy individuals. Am J Clin Nutr, 1990; 51: 241-7

[8] Rao Z, Wu X, Liang B, Wang M, Hu W. Comparison of five equations for estimating resting energy expenditure in Chinese young, normal weight healthy adults. Eur J Med Res, 2012; 17:26.

[9] Ruiz JR, Ortega FB, Rodriguez G, Alkorta P, Labayen I. Validity of Resting Energy Expenditure Predictive Equations before and after an Energy-Restricted Diet Intervention in Obese Women. PLoS One, 2011; 6:e23759.

[10] Frankenfield DC, Rowe WA, Smith JS, Cooney RN. Validation of several established equations for resting metabolic rate in obes e and non-obese people. J Am Diet Assoc, 2003; 103:1152-9.

[11] Weijs PJ. Validity of predictive equations for resting energy expenditure in US and Dutch overweight and obese class I and II adults aged $18-65 y$. Am J Clin Nutr, 2008; 88:959-70.

[12] deOliveria EP, Orsatti FL, Teixeira D, Maesta N, Burini RC. Composition of predictive equations for resting energy expenditure in overweight and obese adults. J Obes, 2011; 2011:534714.

[13] Schofield WN, Schofield C, James WPT. Basal metabolic rate -review and prediction, together with an annotated bibliography of source material. Hum Nutr Clin Nutr, 1985; 39C: 5-96.

[14] Foster G D, McGuckin BG. Estimating resting energy expenditure in obesity. Obes Res, 2001; 9: 367-372s.

[15] Hofsteenge GH, Chinapaw MJM, Delemarre HA, Weijs PJM. Validation of predictive equations for resting energy expenditure in obese adolescents. Am J Clin Nutr, 2010; 91:1244-1254.

[16] Sharp TA, Bell ML, Grunwald GK, Schmitz KH, Sidney S, Lewis CE, Tolan K, Hill JO. Differences in resting metabolic rate between white and African-American young adults. Obes Res, 2002; 10:726-32.

[17] Henry CJK, Rees DG. New predictive equations for the estimation of basal metabolic rate in tropical people. Eur J Clin Nutr, 1991; 45:177-185.

[18] World Medical Association Medical Ethics Committee. Updating the WMA Declaration of Helsinki. Wld Med J, 1999; 45:11 -13

[19] Weyer C, Bogardus C, Pratley RE. Metabolic Factors Contributing to Increased Resting Metabolic Rate and Decreased InsulinInduced Thermogenesis during the Development of Type 2 Diabetes. Diabetes, 1999; 48:1607-14.

[20] Fontvieille AM, Lillioja S, Ferraro RT, Schulz LO, Rising R, Ravussin E. Twenty-four-hour energy expenditure in Pima Indians with type 2 (non-insulin dependent) diabetes mellitus. Diabetologia, 1992; 35:753-759.

[21] Huang KC, Kormas N, Steinbeck K, Loughnan G, Caterson ID. Resting Metabolic Rate in Severely Obese Diabetic and Nondiabetic Subjects. Obes res, 2004; 53:1395-8

[22] Martin K, Wallace P, Rust PF, Gravey WT. Estimation of Resting Energy Expenditure Considering Effects of Race and Diabetes Status. Diabetes Care, 2004; 27:1405-1411.

[23] Gougeon R, Lamarche M, Yale JF, Venuta T. The prediction of resting energy expenditure in type 2 diabetes mellitus is improved by factoring for glycemia. Int J Obes Relat Metab Disord, 2002; 26:1547-52.

[24] Groop LC, Bonadonna RC, DelPrato S, Ratheiser K, Zyck K, Ferrannini E, et al.. Glucose and free fatty acid metabolism in noninsulin-dependent diabetes mellitus:evidence for multiple sites of insulin resistance. J Clin Invest, 1989; 84:205-2013.

[25] Golay A, Swislocki AL, Chen YD, Raeven GM. Relationships between plasma free fatty acid concentration, endogeneous glucose production and fasting hyperglycemia in normal and non-insulin dependent diabetic individuals. Metabolism, 1987; 36:692-696.

[26] Franssila-Kallunki A, Groop L. Factors associated with basal metabolic rate in patients with Type2 (non-insulin-dependent) diabetes mellitus. Diabetologia, 1992; 35:962-966.

[27] Gougeon R, Pencharz PB, Marliss EB. Effect of NIDDM on the kinetics of whole-body protein metabolism. Diabetes, 1994; 43:318-28.

[28] Huggett RJ, Scott EM, Gilbey SG, Stoker JB, Mackintosh AF, Mary DA. Impact of type 2 diabetes mellitus on sympathetic neural mechanisms in hypertension. Circulation, 2003; 108:3097-3101.

[29] Charlton MR, Nair KS. Role of hyperglucagonemia in catabolism associated with type 1 diabetes: effects on leucine metabolism and the resting metabolic rate. Diabetes, 1998; 47:1748-56.

[30] Li AC, Tereszkowski CM, Edwards AM, Simpson JA, Buchholz AC. Published predictive equations overestimate measured resting metabolic rate in young, healthy females. J Am Coll Nutr, 2010; 29:222-7.

[31] Frankenfield D; Roth-Yousey L, Compher C. Comparison of Predictive Equations for Resting Metabolic Rate in Healthy Nonobese and Obese Adults: A Systematic Review. J Am Diet Assoc, 2005; 105: 775-89. 